\title{
Pressure Control of High Pressure Tubing
}

\author{
Shilin Hu${ }^{1}$, Yu Quan ${ }^{2 *}$ \\ ${ }^{1}$ College of Science, Yanbian University, Yanji, China \\ ${ }^{2}$ College of Economics and Management, Yanbian University, Yanji, China \\ Email: ^1074125606@qq.com
}

How to cite this paper: Hu, S.L. and Quan, Y. (2020) Pressure Control of High Pressure Tubing. Open Access Library Journal, 7: e6351.

https://doi.org/10.4236/oalib.1106351

Received: April 24, 2020

Accepted: May 16, 2020

Published: May 19, 2020

Copyright (c) 2020 by author(s) and Open Access Library Inc.

This work is licensed under the Creative Commons Attribution International License (CC BY 4.0).

http://creativecommons.org/licenses/by/4.0/ (c) (i) Open Access

\begin{abstract}
This article focuses on how to control the pressure in the high-pressure tubing. First, an overall analysis of the system is performed to determine the pressure balance conditions of the high-pressure fuel pipe; that is, the mass of fuel flowing out of the high-pressure fuel pipe is equal to the mass of fuel flowing in. This article uses Excel to fit and organize the data in all data processing. When solving differential equations of pressure and density, the fourth-order Runge-Kutta formula is used, and the numerical solution is obtained by MATLAB2017a.
\end{abstract}

\section{Subject Areas}

Chemical Engineering \& Technology, Fluid Mechanics, Petrochemistry

\section{Keywords}

Fuel Pressure, 4th Order Runge-Kutta Formula, MATLAB2017a, Approximation Method

\section{Question Restatement}

Fuel entry and ejection of high-pressure fuel pipes are the basis of the work of many fuel engines. Figure 1 shows the working principle of a high-pressure fuel system. Fuel enters the high-pressure fuel pipe from $A$ through the high-pressure fuel pump and is then ejected from nozzle $B$. The intermittent working process of fuel entry and ejection will cause the pressure in the high-pressure fuel pipe to change, which will cause the deviation of the amount of fuel injected, thus affecting the working efficiency of the engine.

The inner cavity length of a certain type of high-pressure oil pipe is $500 \mathrm{~mm}$; the inner diameter is $10 \mathrm{~mm}$; the diameter of the small hole at the oil supply inlet 
$A$ is $1.4 \mathrm{~mm}$; the length of the oil supply time is controlled by the check valve switch, and the check valve needs to be opened every time. Turn off for $10 \mathrm{~ms}$. The fuel injector works 10 times per second, and the fuel injection time is $2.4 \mathrm{~ms}$ during each operation. The rate of fuel injection from the fuel injection nozzle $B$ when the fuel injector is working is shown in Figure 2.

This article raises the following two questions:

1) The pressure provided by the high-pressure oil pump at the inlet $A$ is constant at $160 \mathrm{MPa}$, and the initial pressure in the high-pressure oil pipe is 100 $\mathrm{MPa}$. If the pressure in the high-pressure oil pipe is to be stabilized at about 100 $\mathrm{MPa}$ as much as possible, how should the opening time of the check valve be adjusted?

2) If the pressure in the high-pressure oil pipe is to be increased from 100 $\mathrm{MPa}$ to $150 \mathrm{MPa}$ and stabilized at $150 \mathrm{MPa}$ after an adjustment process of about $2 \mathrm{~s}$, how should the duration of the check valve be adjusted?

\section{Question Analysis}

The process of fuel pumping into the high-pressure fuel pipe is constantly changing. It is undoubtedly difficult and complicated to try to achieve dynamic balance and analyze it every moment, which is not conducive to the establishment of mathematical models. In order to simplify the model, this dynamic process can be divided into a superposition of many small segments. In order to maintain the pressure of the high-pressure oil pipe stable, the quality of the oil pumped by the high-pressure oil pump should be equal to the quality of the oil sprayed by the fuel injection nozzle. By analyzing and calculating the amount of oil sprayed by the fuel injection nozzle within one working cycle (100 ms), the amount of oil that the high-pressure oil pump needs to pump in the same period of time can be obtained, and the time when the check valve opens is derived.

\section{Assumptions and Explanations about Model Building}

1) The pressure of the high-pressure oil pipe is only restricted by the conditions specified in this article, and we will not discuss other influencing factors.

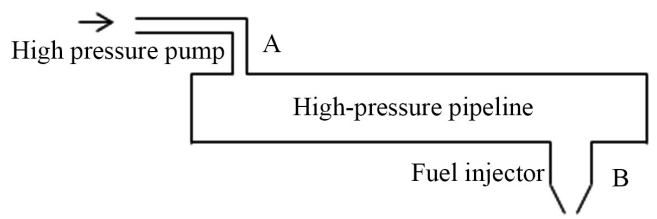

Figure 1. Schematic diagram of high-pressure oil pipe.

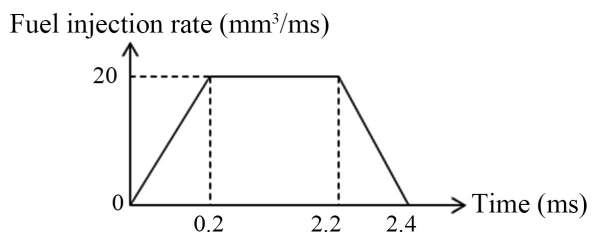

Figure 2. Schematic diagram of fuel injection rate. 
2) The model stipulates that each coefficient is for a general general situation, and we will not discuss other situations.

3) In the analysis of mathematics and physical equations, we set the measurement error to be within the scope of the problem.

4) Ignore fuel leakage, cavitation and temperature changes.

5) At the same moment, the pressure in each point of the high-pressure oil pipe is equal.

6) When calculating the pressure balance, ignore the slight pressure changes in the high-pressure tubing.

7) Regardless of the propagation speed of pressure waves.

Appendix shows the explanation of symbols used in this article.

\section{Modeling and Solving of Questions}

\subsection{Determination of Fuel Pressure and Density}

According to the change of fuel and the change of density is proportional to the proportional coefficient of $\frac{E}{\rho}$, it can be seen that the pressure and density of fuel meet the differential equation:

$$
\frac{\mathrm{d} P}{\mathrm{~d} \rho}=\frac{E}{\rho}
$$

Processing the given data, the fitted curve and correlation are as follows: Figure 3.

Fitting the equation of elastic modulus $E$ with respect to pressure $P$ :

$$
E=0.0001 P^{3}-0.0011 P^{2}+5.47449 P+153.9
$$

Take (5-2) into (5-1) to get the differential equation that pressure $P$ and density $\rho$ satisfy:

$$
\frac{\mathrm{d} P}{\mathrm{~d} \rho}=\frac{0.0001 P^{3}-0.0011 P^{2}+5.47449 P+153.9}{\rho}
$$

It is known that $\rho=0.85 \mathrm{mg} / \mathrm{mm}^{3}$ when $P=100 \mathrm{MPa}$. To solve the above equations, the fourth-order Runge-Kutta formula (RK) method is used. First discretize the equation, generally using the difference quotient to approximate the derivative [1]. Let the differential equation be:

$$
\left\{\begin{array}{l}
\frac{\mathrm{d} y}{\mathrm{~d} x}=f(x, y) \quad a \leq x \leq b \\
y(a)=y_{0}
\end{array}\right.
$$

Let $h_{n}=x_{n+1}-x_{n}$ be called the step size from $x_{n}$ to $x_{n+1}$. Unless otherwise specified, we always take the step size as a constant $h$. If the forward difference quotient $\frac{y\left(x_{n+1}\right)-y(n)}{h}$ is substituted for $y^{\prime}\left(x_{n}\right)$ into the differential equation, then:

$$
\frac{y\left(x_{n+1}\right)-y(n)}{h} \approx f\left(x_{n}, y\left(x_{n}\right)\right) \quad(n=0,1, \cdots, N-1)
$$




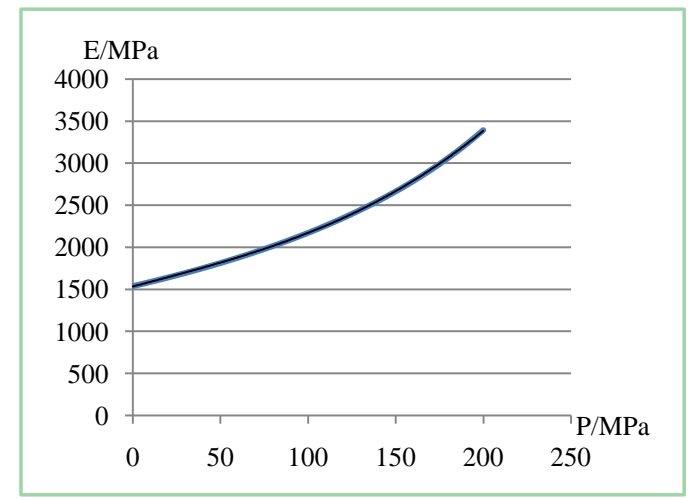

Figure 3. The relationship between $E$ and $P$.

Simplify:

$$
y\left(x_{n+1}\right) \approx y\left(x_{n}\right)+h f\left(x_{n}, y\left(x_{n}\right)\right)
$$

If the approximate value $y_{n}$ of $y\left(x_{n}\right)$ is substituted into the right end of the above formula, the result is taken as the approximate value of $y\left(x_{n+1}\right)$, which is recorded as $y_{n+1}$ :

$$
\left\{\begin{array}{l}
y_{n+1}=y_{n}+h f\left(x_{n}, y_{n}\right) \quad(n=0,1, \cdots, N-1) \\
y_{0}=y(a)
\end{array}\right.
$$

According to the median theorem of differential equations:

$$
\frac{y\left(x_{n+1}\right)-y\left(x_{n}\right)}{h}=y^{\prime}\left(x_{n}+\theta h\right), 0<\theta<1
$$

Note that the equation $y=f(x, y)$ can be obtained:

$$
y\left(x_{n+1}\right)=y\left(x_{n}\right)+h f\left(x_{n}+\theta h, y\left(x_{n}+\theta h\right)\right)
$$

Let $\bar{K}=f\left(x_{n}+\theta h, y\left(x_{n}+\theta h\right)\right)$ be called the average slope in the interval $\left[x_{n}, x_{n+1}\right]$. Taking a few more points in the interval $\left[x_{n}, x_{n+1}\right]$ and using their slope-weighted average as $\bar{K}$, you can construct a calculation formula with better accuracy, the fourth-order Runge-Kutta formula (RK) takes 4 points to construct the following formula [2]:

$$
\left\{\begin{array}{l}
y_{n+1}=y_{n}+h\left(\lambda_{1} k_{1}+\lambda_{2} k_{2}+\lambda_{3} k_{3}+\lambda_{4} k_{4}\right) \\
k_{1}=f\left(x_{n}, y_{n}\right) \\
k_{2}=f\left(x_{n}+\alpha_{1} h, y_{n}+\beta_{1} h k_{1}\right) \\
k_{3}=f\left(x_{n}+\alpha_{2} h, y_{n}+\beta_{2} h k_{1}+\beta_{3} h k_{2}\right) \\
k_{4}=f\left(x_{n}+\alpha_{3} h, y_{n}+\beta_{4} h k_{1}+\beta_{5} h k_{2}+\beta_{6} h k_{3}\right)
\end{array}\right.
$$

Among them, there are 13 undetermined coefficients $\lambda_{i}, \alpha_{j}, \beta_{m}$, which are derived and calculated. Eleven equations with local errors $y\left(x_{n+1}\right)-y\left(x_{n}\right)=O\left(h^{5}\right)$ are obtained. Taking simple $\lambda_{i}, \alpha_{j}, \beta_{m}$ that satisfy these equations [3], we can get: 


$$
\left\{\begin{array}{l}
y_{n+1}=\frac{h}{6}\left(k_{1}+2 k_{2}+2 k_{3}+k_{4}\right) \\
k_{1}=f\left(x_{n}, y_{n}\right) \\
k_{2}=f\left(x_{n}+\frac{h}{2}, y_{n}+\frac{h k_{1}}{2}\right) \\
k_{3}=f\left(x_{n}+\frac{h}{2}, y_{n}+\frac{h k_{2}}{2}\right) \\
k_{4}=f\left(x_{n}+h, y_{n}+h k_{3}\right)
\end{array}\right.
$$

Use MATLAB to calculate the numerical solution of the equation. After writing the data into an Excel file, fit the data to obtain a function image with a correlation coefficient of 1: Figure 4.

\subsection{Calculation of Question (1)}

When $P=160 \mathrm{MPa}$, the fuel density is $0.8711 \mathrm{mg} / \mathrm{mm}^{3}$; when $P=150 \mathrm{MPa}$, $\rho=0.8679 \mathrm{mg} / \mathrm{mm}^{3}$. In order to maintain the stability of the pressure in the high-pressure fuel pipe, the fuel mass flowing into the high-pressure fuel pipe at port A should satisfy $m_{i n}=m_{\text {out }}$. The calculation of the mass of fuel flowing into port $\mathrm{A}$ and the mass of fuel ejected from the fuel injector during a working cycle of the fuel injector is as follows:

$$
\left\{\begin{array}{l}
m_{\text {in }}=Q_{\text {in }} \times \rho_{160} \times t_{\text {total }} \\
Q=C A \sqrt{\frac{2 \Delta P}{\rho}} \\
m_{\text {out }}=44 \times \rho_{100}
\end{array}\right.
$$

Simultaneous calculation of the above equations:

$$
\left\{\begin{array}{l}
m_{\text {out }}=m_{\text {in }}=37.4 \mathrm{mg} \\
t_{\text {total }}=2.8 \mathrm{~ms}
\end{array}\right.
$$

Within $100 \mathrm{~ms}$, the number of inflows is $\frac{100}{t+10}, t$ is the time for each opening, and $t_{\text {total }}$ is the total time for the $A$ port one-way valve to open during one working cycle of the nozzle port, so:

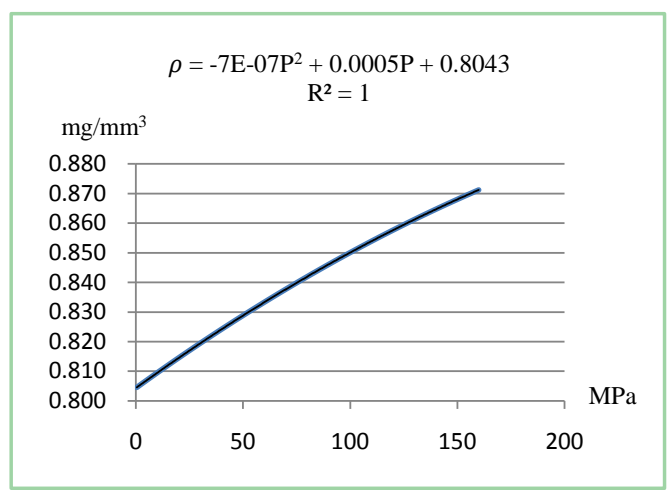

Figure 4. Relationship between $\rho$ and $P$. 


$$
\frac{100}{t+10} \times t=t_{\text {total }}
$$

Therefore, the duration of each valve opening is $t=0.288 \mathrm{~ms}$.

\subsection{Calculation of Question (2)}

In order to make $P$ in the high-pressure tubing from $100 \mathrm{MPa}$ to $150 \mathrm{MPa}$ in $2 \mathrm{~s}$, the pressure task that needs to be increased can be equally divided into each working cycle of the nozzle port in $2 \mathrm{~s}$, so the opening time of the check valve is changed every $100 \mathrm{~ms}$ to The pressure of the high-pressure tubing rises by 2.5 MPa within $100 \mathrm{~ms}$. Let $P_{n}$ be the high pressure tubing pressure.

0 - $100 \mathrm{~ms}$ :

$$
\left\{\begin{array}{l}
m_{\text {in }}=Q \times \rho \times t_{\text {total }} \\
\left(m_{\text {in }}-m_{\text {out }}\right) / V=\rho_{102.5}-\rho_{100} \\
m_{\text {out }}=44 \times \rho_{100} \\
m_{\text {in }}=\rho_{102.5}-\rho_{100} \times V+m_{\text {out }}
\end{array}\right.
$$

where $V$ is the volume of the high-pressure tubing,

$V=500 \times 5^{2} \times \pi=12500 \pi \mathrm{mm}^{3}, P_{1}=100 \mathrm{MPa}$, simultaneous calculation of the above equation:

$$
t_{\text {total_1 }}=\frac{\rho_{102.5}-\rho_{100} \times V+44 \times \rho_{100}}{0.85 \times 0.49 \pi \sqrt{2 \times\left(160-P_{1}\right) \times 0.8711}}
$$

Therefore, the check valve opening time is:

$$
t_{1}=\frac{10 t_{\text {total_1 }}}{100-t_{\text {total_1 }}}
$$

100 - 200 ms: Similarly, we can get:

$$
\begin{gathered}
t_{\text {total_2 }}=\frac{\rho_{105}-\rho_{102.5} \times V+44 \times \rho_{102.5}}{0.85 \times 0.49 \pi \sqrt{2 \times\left(160-P_{2}\right) \times 0.8711}} \\
P_{2}=102.5 \mathrm{MPa} \\
t_{2}=\frac{10 t_{\text {total_2 }}}{100-t_{\text {total_2 }}}
\end{gathered}
$$

$200-300 \mathrm{~ms}:$

‥

1900 - 2000 ms:

$$
\begin{gathered}
t_{\text {total_20 }}=\frac{\rho_{150}-\rho_{147.5} \times V+44 \times \rho_{147.5}}{0.85 \times 0.49 \pi \sqrt{2 \times\left(160-P_{20}\right) \times 0.8711}} \\
t_{20}=\frac{10 t_{\text {total_20 }}}{100-t_{\text {total_20 }}}
\end{gathered}
$$

With this iteration, MATLAB can be used to calculate the adjustment time of the check valve every $100 \mathrm{~ms}$ within the adjustment time of $2 \mathrm{~s}$. In order to stabilize the adjusted pressure at $150 \mathrm{MPa}$, the mass flowing out of the nozzle is 
Table 1. Adjustment table of check valve opening time every $100 \mathrm{~ms}$.

\begin{tabular}{cccc}
\hline \multicolumn{4}{c}{ Total adjustment time 2 s } \\
\hline $\begin{array}{c}\text { Work cycle } \\
(100 \mathrm{~ms})\end{array}$ & $\begin{array}{c}\text { Check valve } \\
\text { opening time }(\mathrm{ms})\end{array}$ & $\begin{array}{c}\text { Work cycle } \\
(100 \mathrm{~ms})\end{array}$ & $\begin{array}{c}\text { Check valve } \\
\text { opening time }(\mathrm{ms})\end{array}$ \\
\hline 1 & 0.599997543 & 11 & 0.768145842 \\
2 & 0.611289684 & 12 & 0.796051254 \\
3 & 0.623415249 & 13 & 0.827681804 \\
4 & 0.636477259 & 14 & 0.863911514 \\
5 & 0.650597192 & 15 & 0.905926936 \\
6 & 0.665919426 & 16 & 0.955386087 \\
7 & 0.68261705 & 17 & 1.014688202 \\
8 & 0.700899583 & 18 & 1.087458477 \\
9 & 0.721023391 & 19 & 1.179483494 \\
10 & 0.743305952 & 20 & 1.300690386
\end{tabular}

equal to the mass flowing in port $A$ within a working cycle, and the opening time of the one-way valve at this time is $t$, then within $100 \mathrm{~ms}$ :

$$
\left\{\begin{array}{l}
m_{\text {out }}=m_{\text {in }} \\
m_{\text {out }}=44 \times \rho_{150} \\
m_{\text {in }}=C A \sqrt{\frac{2 \Delta P}{\rho_{160}}} \times \rho_{160} \times t_{\text {total }}
\end{array}\right.
$$

The calculation is:

$$
t_{\text {total }}=6.992 \mathrm{~ms}, t=0.752 \mathrm{~ms} \text {. }
$$

\subsection{Solution to Questions}

The adjustment scheme of the check valve thus obtained is:

In order to stabilize the pressure of the high-pressure tubing at $100 \mathrm{MPa}$, the opening time of the check valve every $100 \mathrm{~ms}$ should be $t=0.288 \mathrm{~ms}$.

In order to increase the pressure of the high-pressure tubing to $150 \mathrm{MPa}$, when the adjustment time is $2 \mathrm{~s}$, the opening time of the check valve changed every $100 \mathrm{~ms}$ is shown in Table 1.

In order to stabilize the pressure of the high-pressure tubing at $150 \mathrm{MPa}$, the opening time of the check valve every $100 \mathrm{~ms}$ should be $t=0.752 \mathrm{~ms}$.

\section{Evaluation of the Model}

This model achieves reasonable assumptions and is close to actual problems. Compared with other complex and computationally intensive models, it has the advantages of simple and easy to understand and simple programming.

\section{Conflicts of Interest}

The authors declare no conflicts of interest regarding the publication of this paper. 


\section{References}

[1] Breit, D., Feireisl, E. and Hofmanová, M. (2020) Solution Semiflow to the Isentropic Euler System. Archive for Rational Mechanics and Analysis, 235, 167-194. https://doi.org/10.1007/s00205-019-01420-6

[2] Buium, A. and Previato, E. (2017) Arithmetic Euler Top. Joumal of Number Theory, 173, 37-63 https://doi.org/10.1016/j.jnt.2016.09.024

[3] Milici, C., Machado, J.T. and Drăgănescu, G. (2018) On the Fractional Comuspirals. Communications in Nonlinear Science and Numerical Simulation, 67, 100-107. https://doi.org/10.1016/j.cnsns.2018.07.004

\section{Appendix}

\section{Explanation of Symbols Used in This Article}

\begin{tabular}{cc}
\hline Symbol & Definition \\
\hline$P$ & Pressure \\
$E$ & Fuel density \\
$Q$ & Elastic modulus \\
$m_{\text {in }}$ & Fuel flow per unit time \\
$m_{\text {out }}$ & Quality of fuel flowing into high-pressure fuel pipe \\
$C$ & The quality of the fuel from the fuel injection nozzle \\
$A$ & Flow coefficient \\
$V$ & Area of small holes \\
$h$ & Volume of high-pressure oil pipe \\
$S$ & Piston lift \\
& Area of ring hole \\
\hline
\end{tabular}

